\title{
Exposure to novel coronavirus in patients on renal replacement therapy during the exponential phase of COVID-19 pandemic: survey of the Italian Society of Nephrology
}

\author{
Giuseppe Quintaliani ${ }^{1}$ - Gianpaolo Reboldi ${ }^{2}$ - Anteo Di Napoli ${ }^{3} \cdot$ Maurizio Nordio ${ }^{4}$ - Aurelio Limido ${ }^{5}$. \\ Filippo Aucella ${ }^{6}$. Piergiorgio Messa ${ }^{7}$. Giuliano Brunori ${ }^{1,8}$ on behalf of the Italian Society of Nephrology COVID-19 \\ Research Group
}

Received: 9 June 2020 / Accepted: 26 June 2020 / Published online: 3 July 2020

(c) Italian Society of Nephrology 2020

\begin{abstract}
Background Between February and April 2020, Italy experienced an overwhelming growth of the COVID-19 pandemic. Little is known, at the country level, where and how patients on renal replacement therapy (RRT) have been mostly affected. Methods Survey of the network of Nephrology centers using a simplified 17 items electronic questionnaire designed by Italian Society of Nephrology COVID-19 Research Group. We used spatial epidemiology and geographical information systems to map SARS-CoV-2 spread among RRT patients in Italy.

Results On April 9th 2020, all nephrology centers $(n=454)$ listed in the DialMap database were invited to complete the electronic questionnaire. Within 11 days on average, 365 centers responded ( $80.4 \%$ response rate; $2.3 \%$ margin of error) totaling 60,441 RRT patients. The surveyed RRT population included 30,821 hemodialysis (HD), 4139 peritoneal dialysis (PD), and 25,481 transplanted (Tx) patients respectively. The proportion of SARS-CoV-2 positive RRT patients in Italy was $2.26 \%$ (95\% CI 2.14-2.39) with significant differences according to treatment modality $(\mathrm{p}<0.001)$. The proportion of patients positive for SARS-CoV-2 was significantly higher in HD (3.55\% [95\% CI 3.34-3.76]) than PD (1.38\% [95\% CI $1.04-1.78$ ] and Tx $(0.86 \%$ [95\% CI 0.75-0.98]) $(\mathrm{p}<0.001)$, with substantial heterogeneity across regions and along the latitude gradient $(\mathrm{p}<0.001)$. In RRT patients the highest rate was in the north-west $(4.39 \%$ [95\% CI 4.11-4.68], followed by the north-east (IR 2.06\% [1.79-2.36]), the center (0.91\% [0.75-1.09]), the main islands (0.67\% [0.47-0.93]), and the south (0.59\% [0.45-0.75]. During the COVID-19 pandemic, among SARS-Cov-2 positive RRT patients the fatality rate was $32.8 \%$, as compared to $13.3 \%$ observed in the Italian population as of April 23rd.

Conclusions A substantial proportion of the 60,441 surveyed RRT patients in Italy were SARS-Cov-2 positive and subsequently died during the exponential phase of COVID-19 pandemic. Infection risk and rates seems to differ substantially across regions, along geographical latitude, and by treatment modality.
\end{abstract}

Keywords COVID-19 $\cdot$ Hemodialysis $\cdot$ Peritoneal dialysis $\cdot$ Renal transplant $\cdot$ Survey

Giuseppe Quintaliani, Gianpaolo Reboldi and Anteo Di Napoli have contributed equally to the work.

Electronic supplementary material The online version of this article (https://doi.org/10.1007/s40620-020-00794-1) contains supplementary material, which is available to authorized users.

Giuliano Brunori

giuliano.brunori@apss.tn.it

Extended author information available on the last page of the article

\section{Introduction}

Italy was among the countries most severely affected by COVID-19 pandemic [1-3], with an unprecedented and overwhelming growth of active cases and mortality, one of the highest in the world [4]. The first Italian patient with COVID-19 was confirmed on February 21st, 2020 at Codogno Hospital in Lombardy. By early March, the severe acute respiratory syndrome coronavirus 2 (SARS-CoV-2) infection had spread rapidly, yet heterogeneously, throughout the country. A substantial latitude gradient had been reported, with the highest spread in the Northern regions and 
the lowest in the Southern regions and in the main Islands [5].

The relationship between SARS-CoV-2 infection and comorbidity is complex, multifaceted, and further complicated by an unknown number of asymptomatic cases [6]. Nonetheless, severe and deadly cases are most often reported in elderly patients, especially in those with comorbidities [7]. Patients with renal failure are often old and with major comorbidities, thus at increased risk for COVID-19 morbidity and mortality $[8,9]$. Additionally, they often have high levels of contact with health-care facilities and providers for dialysis sessions, clinical monitoring, and supportive care. According to a recent report of the Italian National Institute of Health (Istituto Superiore di Sanità [ISS]), among the most common comorbidities of COVID-19 patients dying in Italy, chronic kidney disease and dialysis are found in $21 \%$ and $2 \%$ of deceased patients respectively [10].

In Italy, preliminary studies confirmed that patients on renal replacement therapy (RRT), especially those on hemodialysis (HD), are particularly vulnerable for severe and fatal COVID-19 [11-15]. Thus far, while several reports and editorials focused on this fragile population [8, 11-15], no large-scale country level study addressed the COVID19 epidemiology in RRT patients. The urgent need for a better understanding of the epidemic in RRT patients was immediately evident, and therefore we designed a survey of the Nephrology centers in Italy, aimed to capture the main features, impact and geographical distribution of SARSCoV-2 spread in over 60,000 prevalent RRT patients during the exponential phase of the COVID-19 pandemic in Italy. We also sought to explore whether RRT modality-specific risks exist for SARS-CoV-2 infection and its consequences.

\section{Methods}

\section{Survey oversight and design}

On March 24th the Italian Society of Nephrology (SIN) Board of Directors constituted a task force and research group (The SIN COVID-19 Research Group) to promote and coordinate, at the national level, epidemiologic studies on the impact of COVID-19 pandemic on Italian Nephrology centers and patients.

As a first initiative to define the impact of the pandemic, the research group designed a fast-response cross-sectional survey. Such design was chosen because it allows to gather data in a narrow time interval and to assemble large amounts of information on a pre-defined number of items, thereby ensuring adequate statistical power and low margin of error. The sampling strategy was based on a convenience sample made of nephrology centers, the primary sampling units
(PSU), listed in the DialMap database [16] with implicit aggregation of prevalent RRT patients within each PSU [17-19].

\section{Instrument and key measures}

All centers were invited to complete a short electronic questionnaire, an instrument designed to obtain $17 \mathrm{key}$ information about patient, workforce and facilities during the exponential phase of COVID-19 pandemic. The questionnaire was internally developed by consensus, and explores five domains: (1) center characteristics (2) test positivity by treatment modality, (3) outcome by treatment modality, (4) preventive measures adopted, (5) policies for SARS-Cov-2 testing.

After an initial pilot study [19] in selected centers [20], the final version of the survey questionnaire was approved by SIN Board of Directors and sent by e-mail on April 9th 2020. The survey deadline date was set for April 23rd 2020. All centers were instructed to input cumulative counts and define the actions taken since February 24th 2020. The study flow-chart and a copy of the questionnaire can be found in the supplementary material (Online Resource 1-Figure S3 and Survey Questionnaire).

\section{Laboratory testing}

In all centers positive cases were identified using a reverse transcriptase-polymerase chain reaction (RT-PCR) test on samples obtained from the upper respiratory tract by nasopharyngeal or oropharyngeal swab. All samples were processed in regional certified laboratories according to procedures specified by the ISS Working Group Diagnostics and Microbiological Surveillance of COVID-19 [21].

\section{Data acquisition and statistical analysis}

For database handling and analysis, we used Microsoft Excel $^{\circledR}$ (Microsoft, WA, USA) and STATA version 15 (StataCorp LLC, TX, USA).

To evaluate the quality and precision of the survey we calculated the response rate (the ratio of respondents to non-respondents) and the margin of error (the maximum expected difference between true population parameters and survey estimates) [18].

Test positive rates, by treatment modality and overall, were estimated using the number of positive cases as numerator and the number of patients as denominator. To calculate fatality rates we divided the number of deaths in persons who tested positive for SARS-CoV-2 by the number of SARS-CoV-2 cases, in keeping with the report of Italian National Institute of Health [3]. Confidence intervals for rates and proportions were calculated using the exact method 
[22]. Poisson regression models were used to explore the association between case counts with region and latitude [23].

\section{Geospatial analysis}

Geographical information system (GIS) technology was used to manage geographic data.

A spatial database was created, with GIS layers of administrative units (regions and provinces) using the Istituto Nazionale di Statistica (ISTAT) shapefiles [24] and the SIN COVID-19 survey observations. A series of GISsupported procedures were implemented to geocode and aggregate data in the corresponding regions. Geospatial mapping, in choropleth style maps, was conducted using $\mathrm{R}$ Software Ver 3.6.3 (R Foundation for Statistical Computing, Vienna, Austria) with centers and RRT patients grouped at the region level [25].

\section{Results}

\section{Centers}

On April 9th 2020, all nephrology centers $(n=454)$ listed in the DialMap database [16] were invited to complete the electronic questionnaire. By the deadline date (April 23rd 2020) 365 centers responded $(80.4 \%$ response rate; $2.3 \%$ margin of error). The national distribution of participating centers is shown in the left panel of Fig. 1.

Preventive measures were adopted by all surveyed centers using personal protective equipment (PPE) and gloves for all patients and staff. Diagnostic testing policies varied across centers (Online Resource 1-Figure S1). The surveyed centers adopted a "test-all" policy more frequently for health care professional $(30 \%)$ than for patients $(16 \% ; \mathrm{p}<0.001$ for the proportions difference). Conversely, patients were more likely to be tested than health-care professionals if symptomatic ( $58 \%$ vs. $42 \%$ respectively; $p<0.001$ for the proportions difference). All surveyed centers did in person triage and modified access policies, while 227 centers, out of 365 , systematically contacted patients (telephone triage) during the interdialytic interval. The vast majority of the centers $(321 / 365 ; 88 \%)$ modified transport policies, using individual transport for suspected and/or confirmed cases in HD patients.

\section{SARS-Cov-2 positive cases}

The survey population included 30,821 hemodialysis (HD), 4139 peritoneal dialysis (PD), and 25,481 kidney transplant (Tx) patients, totaling 60,441 RRT patients (Fig. 1, right panel). There were 1368 SARS-CoV-2 positive cases out of the 60,441 RRT patients surveyed (Fig. 2) with an overall rate of $2.26 \%$ (95\% CI 2.14-2.39). There were significant differences $(\mathrm{p}<0.001)$ according to treatment modality. As shown in Table 1, the number

\section{SIN COVID-19 Survey}
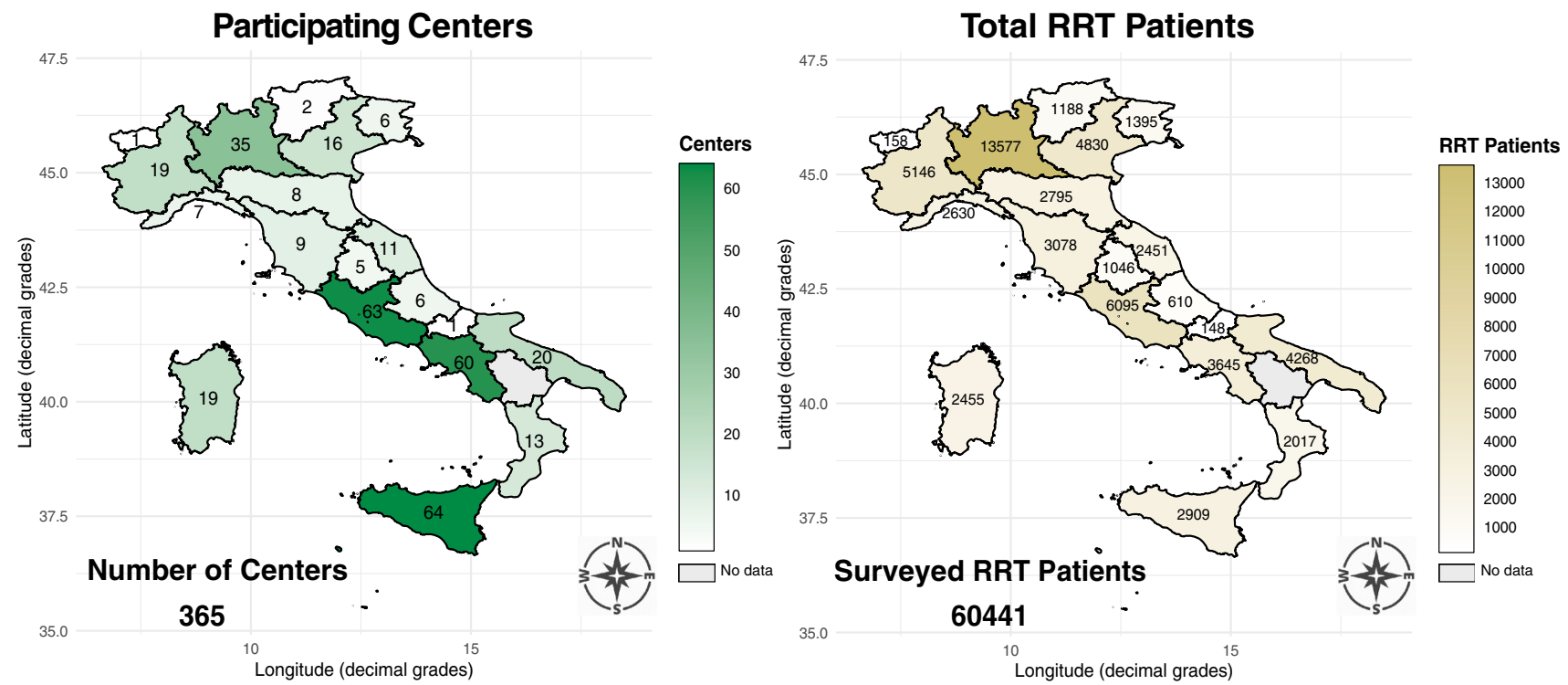

Fig. 1 Choropleth map of the regional distribution of the 365 surveyed centers (left panel) and the 60,441 surveyed patients on renal replacement therapy (RRT) (right panel) 
Fig. 2 Map of SARS-CoV-2 positive cases in the 60,441 surveyed renal replacement therapy (RRT) patients observed from February 24th to April 23rd 2020

\section{SARS-CoV-2 Postive RRT patients}

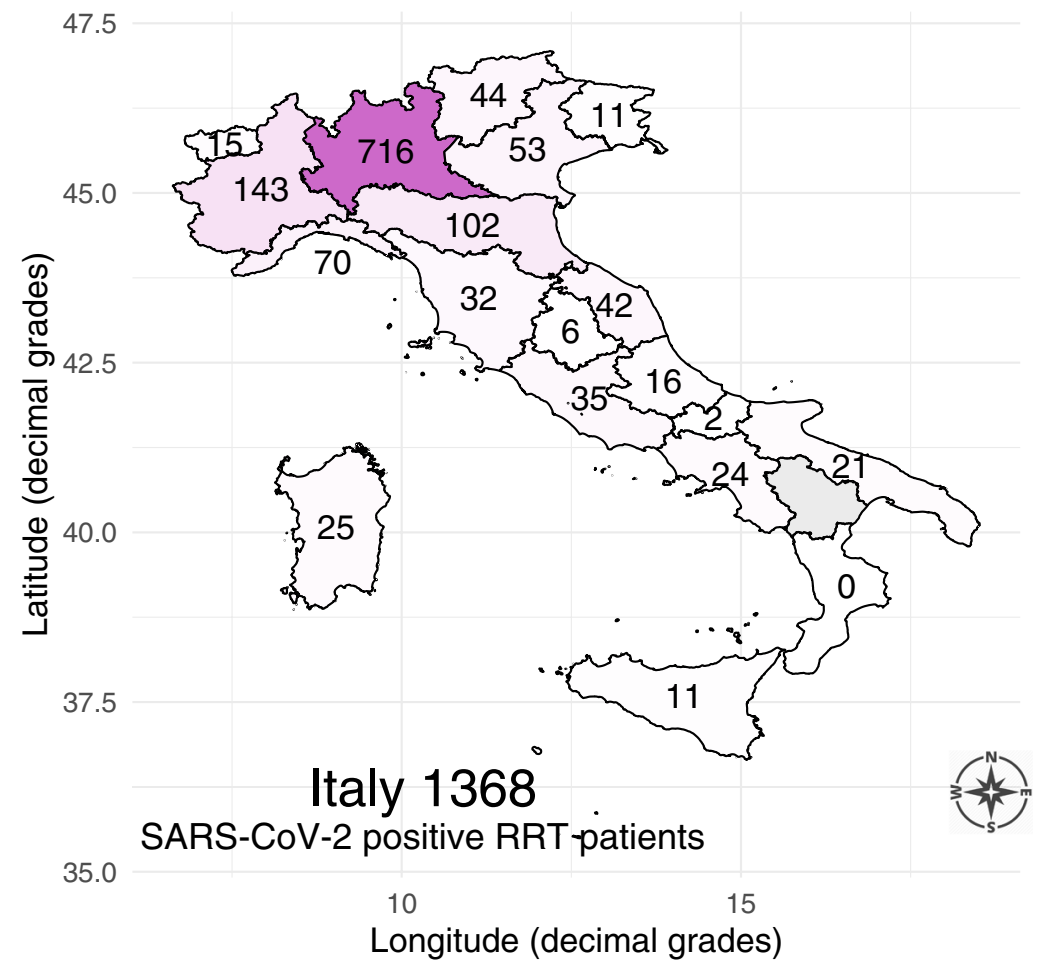

N. of cases

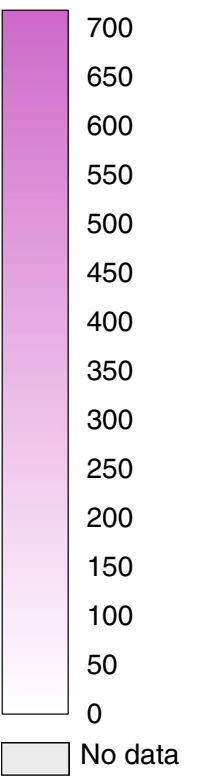

Table 1 Exposed patients, SARS-CoV-2 positive cases and incidence rate by treatment modality and overall

\begin{tabular}{lcclll}
\hline $\begin{array}{l}\text { Treatment } \\
\text { modality }\end{array}$ & Exposed patients & $\begin{array}{l}\text { SARS-CoV-2 } \\
\text { positive cases }\end{array}$ & IR per 100 & 95\% CI \\
\hline HD & 30,821 & 1093 & 3.55 & 3.34 & 3.76 \\
PD & 4139 & 57 & 1.38 & 1.04 & 1.78 \\
Tx & 25,481 & 218 & 0.86 & 0.75 & 0.98 \\
RRT & 60,441 & 1368 & 2.26 & 2.14 & 2.39 \\
\hline
\end{tabular}

$H D$ hemodialysis, $P D$ peritoneal dialysis, $T x$ transplant, $R R T$ renal replacement therapy, $I R$ incidence rate

of positive cases was higher in HD $(1093 / 30,821)$ than PD $(57 / 4139)$ and Tx $(218 / 25,481)$ respectively. The rate of positive cases exhibited substantial and significant heterogeneity along the latitude gradient $(p<0.001)$. In RRT patients the highest rate was in the north-west (4.39\% [95\% CI 4.11-4.68]), followed by the north-east (2.06\% [1.79-2.36]), the center $(0.91 \%$ [0.75-1.09]), the main islands $(0.67 \%$ [0.47-0.93]), and the south $(0.59 \%$ [0.45-0.75]). At finer level of geographical aggregation, significant heterogeneity $(\mathrm{p}<0.001)$ persisted for all treatment modalities (Fig. 3).

\section{Hemodialysis}

In the north-west regions SARS-CoV-2 positivity rates in HD were higher than the national average $(7.65 \%$ vs. $3.55 \% ; \mathrm{p}<0.001)$ but with substantial heterogeneity (Table 2; Fig. 3 panel A). Interestingly, north-east regions had lower rates than the north-west ones $(3.30 \%$ vs. $7.65 \%$; $\mathrm{p}<0.001)$. In central Italy SARS-CoV-2 positivity rate was, on average, $1.39 \%$ (95\% CI 1.12-1.71) but rates higher than expected were observed in Toscana $(3.42 \%$ [95\% CI 2.27-4.94]) and Marche (2.50\% [95\% CI 1.63-3.66]). Starting from Umbria down south, and across the main islands, rates were generally lower than $1 \%$ with two notable extremes: Calabria with no SARS-CoV-2 positive cases, and Abruzzo with the highest positivity rate $(4.67 \%$ [95\% CI 2.62-7.71]).

\section{Peritoneal dialysis}

Compared to HD, SARS-CoV-2 positive cases were less frequent among PD patients $(1.38 \%$ vs $3.55 \%$; $p<0.001$; Table 3; Fig. 3 panel B) with 57 total cases, out of which two thirds were observed in four regions: Lombardia (17), Veneto (8), Piemonte (7) and Marche (6). In six regions no cases were registered. 


\section{SARS-CoV-2 Infection Rates by Modality}

\section{A) Hemodialysis}

B) Peritoneal Dialysis

C) Transplant

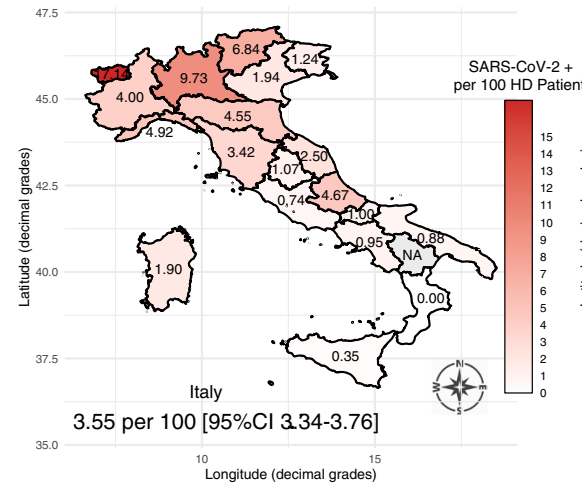

Region effect $\mathrm{p}<0.001$ Latitude effect $p<0.001$

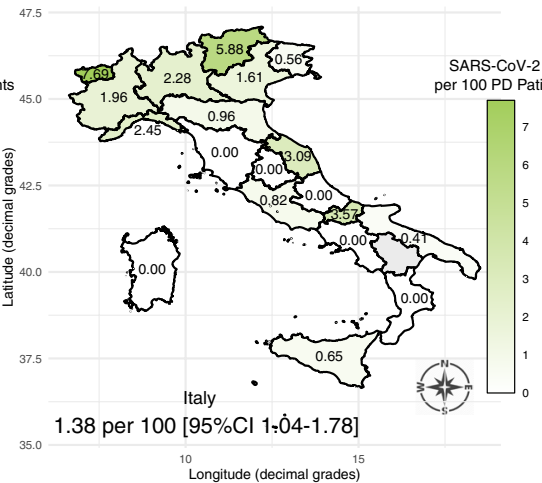

Region effect $p<0.001$ Latitude effect $p<0.001$

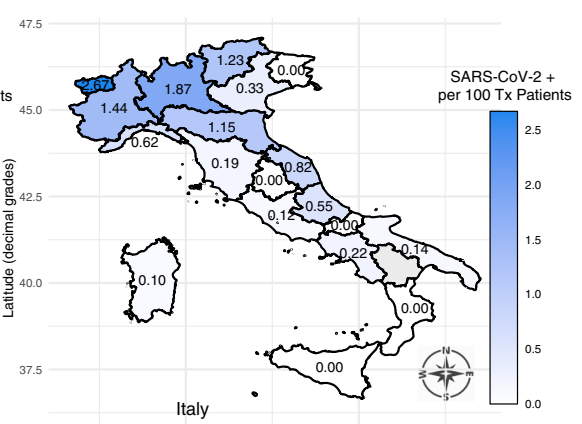

0.86 per 100 [95\% $\%$ Cl $\dot{7} 6-0.99]$

${ }_{\text {Longitude (decimal grades) }}^{10}$

Region effect $p<0.001$ Latitude effect $p<0.001$

Fig. 3 Map of the regional distribution of SARS-CoV-2 infection rates by renal replacement modality: a hemodialysis (HD); b peritoneal dialysis (PD); c transplant (Tx)

Table 2 SARS-CoV-2 incidence rates in hemodialysis patients by geographical macro-region and nationally

\begin{tabular}{lclll}
\hline Macro-region & $\begin{array}{l}\text { Exposed HD } \\
\text { patients }\end{array}$ & IR per 100 & 95\% CI & \\
\hline North-West & 9717 & 7.65 & 7.11 & 8.22 \\
North-East & 5242 & 3.30 & 2.83 & 3.83 \\
Center & 6462 & 1.39 & 1.12 & 1.71 \\
South & 5567 & 0.97 & 0.73 & 1.27 \\
Main Islands & 3833 & 0.86 & 0.59 & 1.21 \\
Italy & 30,821 & 3.55 & 3.34 & 3.76 \\
\hline
\end{tabular}

$H D$ hemodialysis, $I R$ incidence rate

Table 3 SARS-CoV-2 incidence rates in peritoneal dialysis patients by geographical macro-region and nationally

\begin{tabular}{lclll}
\hline Macro-region & $\begin{array}{l}\text { Exposed PD } \\
\text { patients }\end{array}$ & IR per 100 & 95\% CI & \\
\hline North-West & 1281 & 2.26 & 1.52 & 3.25 \\
North-East & 952 & 1.58 & 0.88 & 2.60 \\
Center & 791 & 1.14 & 0.52 & 2.16 \\
South & 626 & 0.32 & 0.04 & 1.15 \\
Main Islands & 489 & 0.41 & 0.05 & 1.48 \\
Italy & 4139 & 1.38 & 1.04 & 1.78 \\
\hline
\end{tabular}

$P D$ peritoneal dialysis, $I R$ incidence rate
Table 4 SARS-CoV-2 incidence rates in transplant patients by geographical macro-region and nationally

\begin{tabular}{lclll}
\hline Macro-region & $\begin{array}{l}\text { Exposed Tx } \\
\text { patients }\end{array}$ & IR per 100 & 95\% CI & \\
\hline North-West & 10,513 & 1.64 & 1.40 & 1.90 \\
North-East & 4014 & 0.55 & 0.34 & 0.83 \\
Center & 5417 & 0.29 & 0.17 & 0.48 \\
South & 4495 & 0.16 & 0.06 & 0.32 \\
Main Islands & 1042 & 0.10 & 0.00 & 0.53 \\
Italy & 25,481 & 0.86 & 0.75 & 0.98 \\
\hline
\end{tabular}

$T x$ transplant patients, $I R$ incidence rate

\section{Kidney transplant}

The north-to-south geographical gradient of SARS-CoV-2 positive cases was confirmed also for Tx patients (Table 4; Fig. 3 panel C), even though the overall rate $(0.86 \%$ [95\% CI 0.76-0.99]) was the lowest observed among treatment modalities. About three-quarters of the 218 SARS-Cov- 2 positive Tx patients were observed in two regions: Lombardia (131) and Piemonte (31). In five regions no cases were registered.

\section{Case fatality}

There were 449 deaths among 1368 SARS-CoV-2 positive RRT patients, with an overall case fatality rate (CFR) of $32.82 \%$ (95\% CI 29.9-36.0). However, there were substantial 
Table 5 Number of deaths and fatality rates in 1368 SARS-CoV-2 positive patients by treatment modality and overall

\begin{tabular}{lcrlll}
\hline Treatment & $\begin{array}{l}\text { SARS-CoV-2 } \\
\text { positive patients }\end{array}$ & Deaths & $\begin{array}{l}\text { Fatality } \\
\text { rate per } \\
100\end{array}$ & $95 \%$ CI & \\
\hline HD & 1093 & 369 & 33.76 & 30.43 & 37.42 \\
PD & 57 & 26 & 45.61 & 29.80 & 66.83 \\
Tx & 218 & 54 & 24.77 & 18.61 & 32.32 \\
RRT & 1368 & 449 & 32.82 & 29.86 & 36.00 \\
\hline
\end{tabular}

$H D$ hemodialysis, $P D$ peritoneal dialysis, $T x$ transplant, $R R T$ renal replacement therapy

and significant differences (Table 5) among treatment modalities ( $\mathrm{p}<0.001)$. Specifically, CFR was $33.76 \%$ in HD, $45.61 \%$ in $\mathrm{PD}$, and $24.77 \%$ in Tx patients.

\section{Hemodialysis}

Out of 1069 SARS-CoV-2 positive HD, 369 died.

The geographical distribution of fatality rates among SARS-CoV-2 positive HD patients (Fig. 4) was not influenced by latitude $(\mathrm{p}=0.653)$ or region-specific effect $(\mathrm{p}=0.243)$. Restricting the analysis to the regions where at least 10 deaths were observed, accounting for 333 fatal cases $(86.6 \%)$, the rates remained well above $25 \%$ (Online
Resource 1-Table S1). Only two regions reported no deaths among SARS-CoV-2 positive HD patients.

\section{Peritoneal dialysis}

Out of 57 SARS-CoV-2 positive PD patients, 26 died (Table 5). Although on sparse counts (Online Resource 1Table S2), this was the highest national fatality rate (CFR $45.61 \%$ [95\% CI 29.80-66.83]).

\section{Kidney transplant}

Out of 218 SARS-CoV-2 positive Tx patients 54 died with a $24.77 \%$ fatality rate, the lowest among treatment modalities (Table 5). The highest toll was paid by Lombardia (26) and Piemonte (13), collectively 39 out of 54 total deaths (Online Resource 1-Table S3).

\section{Discussion}

In the last few months, Italian nephrologists have been contrasting the overwhelming COVID-19 pandemic with all available means and strategies, including stringent containment measures, extensive diagnostic testing, especially in high risk patients, and by sharing the latest information transparently and promptly [8, 10, 26].
Fig. 4 Regional map of case fatality rates (CFR) in SARS$\mathrm{CoV}-2$ positive hemodialysis (HD) patients

\section{Case Fatality Rate per 100 SARS-CoV-2 positive HD Patients}

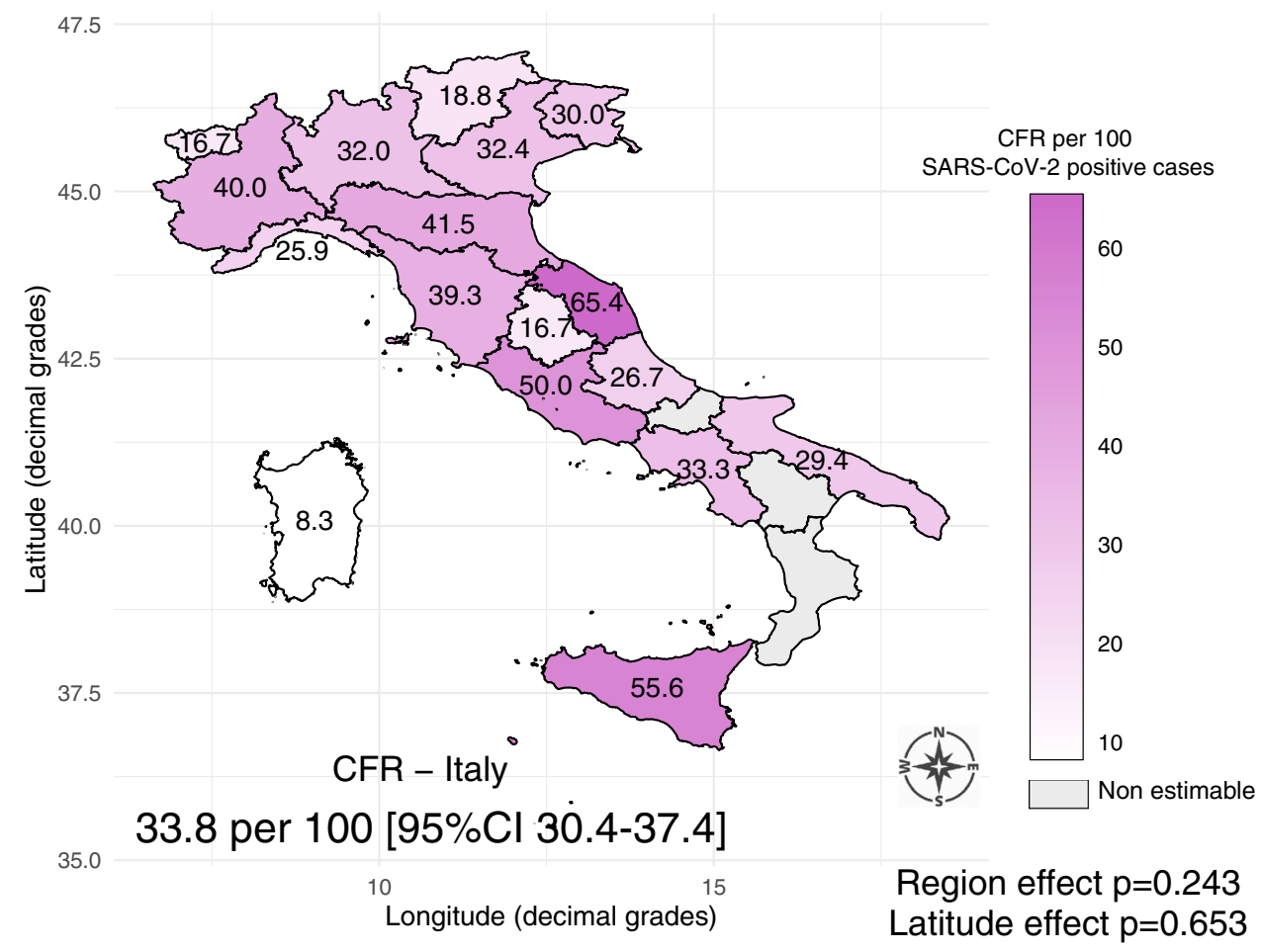


The impact and burden of COVID-19 pandemic on the Nephrology community in Italy was indeed a "life-changing experience" [27]. Recommendations to contain the spread of infection in RRT patients have been quickly posted [28-30], but little is known on the outcomes at the country and regional levels, where the pandemic appears to spread with varying degrees of intensity [11, 12, 14, 31].

The Italian Society of Nephrology COVID-19 Survey is the first initiative fostering a national research collaboration on the pandemic impact on RRT patients and centers.

Overall, the survey shows that a significant proportion of RRT patients are SARS-Cov-2 positive, in settings where most of the tests were done in symptomatic patients. Positivity rates showed significant heterogeneity among regions $(\mathrm{p}<0.001)$ as well as along the country latitude gradient $(\mathrm{p}<0.001)$. Such heterogeneity might depend upon several factors including the local rate of infection spread and burden, the type and effectiveness of containment measures, and the testing strategies adopted. Besides, the scattering of local outbreaks along the latitude, temperature, and humidity gradients is fairly consistent with the spread of seasonal respiratory virus infections [32, 33]. Nonetheless, our descriptive findings deserve further investigation, since, if causal links will be established, they might have significant impact on future containment and lockdown policies.

Fewer PD and Tx patients tested positive for SARSCoV-2. Unlike HD, PD and Tx patients refer to nephrology centers for scheduled visits, typically a few weeks apart, while continuing treatment at home, thus limiting the exposure [11, 12, 15]. Moreover, home treated patients, as well as their caregivers, are usually well trained and acquainted with effective measures to reduce infection risk. Incidentally, telemedicine and remote consulting [28, 34] might have further contributed to reduce the risks in these cases.

The fatality rate was impressively high: $34 \%$ among HD patients with no substantial differences across and along the country. Such figure is 2.5 times higher than the $13.3 \%$ overall case-fatality rate estimated in Italy as of April 23rd [5]. Interestingly, even though the absolute number of deaths in central and southern regions was lower than in northern Italy, the regional rates were larger than expected. The huge death toll paid by HD patients in the first 2 months of the pandemic is likely due to the inherent clinical characteristics of HD patients such as advanced age, major comorbidities and frailty status. Of note, fatality rates remained substantially higher than expected, even though with wide confidence intervals, also among PD and Tx patients (45\% and 25\% respectively). With all due caution, our findings collectively suggest that even at low infection rates, as observed in PD and Tx, fatal outcomes are common among SARS-Cov-2 positive RRT patients.
Finally, while hospitals and facilities were tackling an overwhelming pandemic, Nephrologists had also to treat COVID-19 related acute kidney injury (AKI) [35, 36]. The surveyed centers reported 607 AKI cases requiring RRT in intensive care units (Online Resource-Figure S2). The prompt response of nephrology teams in emergency settings must be recognized [37], and we believe that the timely recommendations endorsed by the Italian Society of Nephrology [26] provided a comprehensive and continuously updated guidance.

The present survey has the strength of covering the majority of the RRT centers and patients in a nation that was heavily confronted by the COVID-19 pandemic, but also has some limitations. The findings should be interpreted judiciously because the centers database, on which the study was built, is primarily used for administrative management rather than research. Given the limited resources available and the time-sensitivity of the COVID-19 pandemic, we adopted a non-probability sampling strategy. Nonetheless, since the survey response rate was over $80 \%$, with a small margin of error (2.3\% at the $95 \%$ confidence level), and covered over $90 \%$ of the country territory, the estimates can be considered reliable and precise with low uncertainty.

\section{Conclusions}

Nationwide and international collaboration, such as the Italian Society of Nephrology COVID-19 Research project, are extremely important to support the development of effective strategies to reduce the burden of severe and potentially fatal disease among RRT patients $[8,28]$. The Italian Society of Nephrology COVID19 survey confirms and extends previous preliminary observations suggesting that RRT patients, especially those on HD, are at increased risk of developing severe SARS-Cov-2 infections. Conversely, home treated patients are at lower risk of being infected. While positivity rates showed a significant latitude and region effect, in keeping with what was observed in the general population, these factors did not affect death rates, suggesting that fatality is inherently linked to RRT status and related comorbidities. Our findings support and reinforce the current recommendations of the Italian Society of Nephrology $[28,31]$ on prompt, effective and meticulous care of RRT patients, to reduce the risk of SARS-Cov-2 infection and its adverse prognostic implications [12-14, 28, 30, 31].

Acknowledgements We thank Mrs. Claudia Valletta for her excellent secretarial assistance and for contributing to the survey data collection. We extend our gratitude to the Journal of Nephrology editors and reviewers for their thoughtful comments and suggestions. 


\section{Compliance with ethical standards}

Conflict of interest The authors declare that there is no conflict of interest.

Ethical approval All data used in this study were collected anonymously and in accordance with the ethical standards of the institutional and regional research committees, with the 1964 Helsinki Declaration and its later amendments or comparable ethical standards. The study did not require formal individual consent because it was conducted on aggregate data.

\section{Appendix}

\section{Italian Society of Nephrology COVID-19 Research Group}

\section{Italian Society of Nephrology Board of Directors}

Giuliano Brunori, Piergiorgio Messa, Filippo Aucella, Manuela Bosco, Fabio Malberti, Marcora Mandreoli, Sandro Mazzaferro, Ezio Movilli, Giuseppe Quintaliani, Maura Ravera, Mario Salomone, Domenico Santoro

2. DialMap

Maurizio Postorino, Aurelio Limido

3. Participating Centers and Investigators by Region: Abruzzo:

Chieti (M. Bonomini); Ortona-Guardagriele (A. Stingone); Lanciano Casoli Atessa (M. Maccarone); PO Atri (E. Di Loreto); Giulianova (L. Stacchiotti); Teramo (R. Malandra);

Calabria: Area Ionica Soverato-Catanzaro (S. Chiarella); Lamezia Terme (F. D'Agostino); AOU Mater Domini-Catanzaro (G. Fuiano); PO Rossano-Rossano (CS) (L. Nicodemo); Osp. Annunziata Cosenza-Rete emodialitica territoriale-Asp di Cosenza-Cosenza (R. Bonofiglio); Crotone (S. Greco); Reggio Calabra (F. Mallamaci); Scilla (E. Barreca); Melito Porto Salvo (C. Caserta); Taurianova (V. Bruzzese); Serra San Bruno-Soriano Calabro (D. Galati); Vibo Valentia (D. Tramontana);

Campania: AO Moscati Avellino (M. Viscione); Dyalisis-Capodicasa (L. Chiuchiolo); Solofra (S. Tuccillo); Emodialisi Irpina Grottaminarda (M. Sepe); Osp. Ariano Irpino (F. Vitale); PO Santa Maria della Pietà-Nola (E. Ciriana); Dialisi Alra Irpinia Calitri (D. Santoro); AO G. Rummo-Benevento (V. Martignetti); AORN Caserta-Caserta (D. Caserta); Adem Marcianise-Marcianise (A. Stizzo); Helios Capua (A. Romano); SSD ASL Caserta-San Felice a Cancello (G. Iulianiello); Emodialisi Ludial-Castel Volturno (E. Cascone); Polisan San Nicola La Strada (P.
Minicone); Emodialisi Cedial Santa Maria Capua Vetere (D. Chiricone); Emodialisi Luna Teano (G. Delgado); Vairano Patenora Caserta (A. Barbato); DIALCA SRL Caiazzo (S. Celentano); Cedial Sessa Aurunca (I. Molfino); PO Piedimonte Matese (S. Coppola); Iatreion Caserta (I. Raiola); Diam NefrocenterMaddaloni (M. Abategiovanni); Centro AtellanoOrta di Atella (CE) (S. Borrelli); Renart-Casagiove (C. Margherita); Nefrodial-Aversa (F. Bruno); Cedial Srl-San Cipriano D'Aversa (M. Ida); Alma CenterMariglianella (E. Aliperti); CGA-Giugliano in Campania (D. Potito); CMO-Gragnano (G. Cuomo); Ambulatorio Emodialisi-Mugnano di Napoli (M. De Luca); Seironos-Sorrento (M. Merola); DIAL 3-Arzano (NA) (C. Botta); Nephrocare-Napoli (G. Garofalo); AO Cardarelli-Napoli (P. Alinei); Osp. Del Mare-Napoli (C. Paglionico); Dialgest-Casoria (M. Roano); Gruppo Dialisi Campano-Frattamaggiore (S. Vitale); Centro Delta-Boscoreale (R. Ierardi); CNP Frattamaggiore-Frattamaggiore (v. Fimiani); PO Santa Maria degli Incurabili Univ. Vanvitelli-Napoli (G. Conte); Ospedale Pellegrini-Napoli (G. Di Natale); Emodialisi Vesuviana-San Giuseppe Vesuviano (M. Romano); Gestione Servizi Emodialisi-Pozzuoli (V. Di Marino); Dial Cast Srl—Santa Maria La Carità (NA) (A. Scafarto); Villa S. Andrea-Napoli (S. Meccariello); AO Santobono Pausilipon-Napoli (C. Pecoraro); Cendial-Acerra (E. Di Stazio); Ischia (E. Di Meglio); Emodialisi EURODIAL—Napoli (A. Cuomo); Sean Srl-Aversa (B. Maresca); S. Pio X-Afragola (E. Rotaia); Nefrologia e Dialisi Univ. Vanvitelli-Napoli (G. Capasso); San Leonardo ASL NA3 SUD (M. Auricchio); D. Cotugno AORN dei Colli-Napoli (C. Pluvio); Kidney-Casavatore (L. Maddalena); CMMCava dei Tirreni (A. De Maio); AO Ruggi Mercato San Severino-Ospedale Ruggi Salerno (G. Palladino); PO Polla (F. Buono); Eboli (G. Gigliotti);

Emilia Romagna: Imola (M. Mandreoli); Malpighi e S. Orsola-Bologna (E. Mancini. G. La Manna); Cona-Ferrara (A. Storari); Forlì-Cesena (G. Mosconi); Modena AUSL Carpi (G. Cappelli); Piacenza (R. Scarpioni); Reggio Emilia (M. Gregorini); Rimini (A. Rigotti);

Friuli Venezia Giulia: Pordenone (W. Mancini); Trieste (F. Bianco); Santa Maria della MisericordiaUdine (G. Boscutti); San Daniele-Tolmezzo (G. Amici); Palmanova-Latisana-Gorizia-Monfalcone (M. Tosto);

Lazio: Frosinone Ospedale-Anagni Osp FR (R Fini); Euronefro Frosinone (G. Pace); Sora Ospedale FR (R. Simonelli); Sant'Elisabetta Fiuggi (E. Boccia); Parodi Delfino Osp Colleferro (L. Di Lullo); NephroCare di Cassino (A. D’Apollo); Cassino Ospedale (R. Simonelli); 
Alatri Ospedale (R. Fini); Centro dialisi Città di Aprilia (L. Miglio); Osp S Maria Goretti Latina-Cisterna di Latina (N. Rifici); Dono Svizzero Formia (A. Treglia); I.C.O.T.-Giomi (M. Muci); Centro Dialisi Monte San Biagio (G. Baldinelli); Only Dialysis Clinics (E. Rizzi); Centro Dialisi Italian Hospital Group Guidonia (M. Lonzi); Casa di Cura Ars Medica 2 (C. De Cicco); Nuova Clinica Annuziatella (G. Silvestrini); Ospedale San Camillo Forlanini-San Camillo su Spallanzani (P. De Paolis); Policlinico Agostino Gemelli (G. Grandaliano); Casa di cura ARS Medica Dialisi 1 (C. Cuzziol); Centro Dialisi Geramed di Fiano Romano (V. Lacava); Clinica Madonna delle Grazie Velletri (P. Sfregola); Medica San Carlo Frascati (V. Rossi); Santo Spirito in Sassia (F. Gangeri); Ladispoli (A. Flammini); Policlinico Casilino (A. Filippini); Clinica Città di Roma L. Onorato); Casa di Cura Privata Nostra Signora della Mercede (F. Vendola); Policlinico Tor Vergata (N. Di Daniela); Diagest (C. Alfarone); Casa di cura Nuova Villa Claudia A (L. Scabbia); Ospedale dei Castelli RM6 (M. Ferrazzano); Casa di Cura Villa dei Pini Gruppo ASA (B. Della Grotta); San Giovanni Addolorata (M. Gamberini); Casa di Cura Nuova ITOR A e B L. Fazzari); Azienda Ospedaliera Sant'Andrea (P. Menè); Villa Nina Marino (A. Morgia); Regina Apostolorum-Albano Laziale (A. Catucci); S. Eugenio CTO S Caterina (R. Palumbo); Osp Palestrina Coniugi Barberini (M. Puliti); Casa di Cura Madonna della Fiducia (R. Marinelli); Osp S Giovanni Evangelista Tivoli/Subiaco (P. Polito); Capena-BraccianoCivitavecchia San Paolo RM4 (F. Marrocco); AOU Policlinico Umberto I-UOD Dialisi/UOC Nefro (S. Mazzaferro); MIRA-NEPHRO SRL Ambulatorio di Nefrologia e Dialisi "Città di Ardea" (L. Nazzaro); NeproCare Cer. Lab. (R. Lavini); Villa Tiberia Hospital (V. Iamundo); Fatebenefratelli (M. Chiappini); Casa di cura Nuova Villa Claudia B (M. Casarci); PO asl3 OSTIA (M. Morosetti); Villa Sandra (S. Hassan); Villa Annamaria (A. Nigro); Anzio-Nettuno (C. Mazzoni); Clinica Guarnieri (G. Firmi); Ospedale Sandro Pertini/ UDD DonBosco (M. Galliani); Ambulatorio Dialisi Nephrocare-Nephronet di Pomezia (M. Serraiocco); VT Osp Belcolle-S Teresa-Tarquinia- Civita Castellana (S. Feriozzi); ASL Rieti (W. Valentini);

Liguria: ASL 3 Genova Osp. Villa Scassi e Arenzano (P. Sacco); San Martino-Genova (G. Garibotto); Sestri Levante (V. Cappelli); ASL 1 Imperia Sanremo Ventimiglia (C. Saffioti); ASL2 Savona Albenga Cairo Montenotte (M. Repetto); La Spezia; ASL 5 (D. Rolla);

Lombardia: Policlinico San Marco-Zingonia (M. Lorenz); Seriate (L. Pedrini); Esine-Valcamonica (D. Polonioli); ASST Bergamo Ovest-Treviglio (E. Galli); Papa Giovanni XXIII-Bergamo (P.
Ruggenenti); Brescia (S. Bove); ASST del Garda Manerbio-Desenzano-Gavardo (E. Costantino); ASST Franciacorta (M. Bracchi); ASST Lariana Como-Como (S. Mangano); ASST Crema-Crema (G. Depetri); Cremona (F. Malberti); Lecco (V. La Milia); Lodi (M. Farina); Mantova (S. Zecchini); Garbagnate Milanese (R. Savino); Ospedale San Raffaele-Milano (M. Melandri); ASST Ovest Milanese-Legnano (C. Guastoni); ASST Santi Paolo e Carlo-Milano (M. Paparella); Ospedale Fatebenefratelli-Milano; Ospedale Sacco-Milano (M. Gallieni); NiguardaMilano (E. Minetti); Cernusco sul Naviglio (S. Bisegna); Policlinico Milano (M. Piergiorgio); Vimercate M. Righetti); Humanitas-Rozzano (S. Badalamenti); ASST Ovest Milanese-Magenta (C. Guastoni); ASST Nord Milano Bassini-Milano (E. Alberghini); IRCCS Multimedica-Sesto San Giovanni (S. Bertoli); Ospedale San Gerardo e Desio-Monza (P. Fabbrini); ASST Pavia-Voghera-Stradella-Varzi; (P. Albrizio); San Matteo-Pavia (T. Rampino); Sondrio (C. Colturi); Varese (R. Giuseppe); ASST Valle Olona-BustoGallarate-Saronno (A. Lucatello);

Marche: Fabriano (E. Guerrini); Ancona (A. Ranghino); Ancona INRCA (F. Lenci); Senigallia (E. Fanciulli); Jesi (S. Santarelli); Ascoli Piceno e San Benedetto del T. (C. Damiani); Fermo-Amandola (D. Garofalo); Macerata (F. Sopranzi); Civitanova MarcheRecanati (A. Santoferrara); Pesaro-Fano (M. Di Luca); Urbino (P. Galiotta);

Molise: Campobasso (M. Brigante);

Piemonte: Alessandria (M. Manganaro); Asti (S. Maffei); Biella (I. Berto); ASL CN1 (L. Besso); Alba (G. Viglino); AO S. Croce e Carle-Cuneo (L. Besso); Borgomanero (S. Cusinato); Novara (D. Charinotti); ASL TO3 Rivoli Pinerolo (f. Chiappero); AOU San Luigi-Orbassano (G. Tognarelli); OIRM Dialisi Pediatrica-Torino (B. Gianoglio); ASL TO5Chieri (M. Salomone); Ospedale Giovanni BoscoTorino (G. Forneris); AOU Città della Salute e della Scienza-Torino (L. Biancone); ASL TO4 (S. Savoldi); AO Ordine Mauriziano-Torino (C. Vitale); Torino Martini (R. Boero); Vercelli (O. Filiberti); ASL VCO (M. Borzumati);

Puglia: Policlinico Bari (L. Gesualdo); Osp. MiulliAcquaviva (BA) (C. Lomonte); CAD Monopoli Putignano-Conversano-Gioia del Colle (G. Gernone); Ospedale della Murgia Altamura (G. Pallotta); ASL BT-Bisceglie (S. Di Paolo); ASL Brindisi (L. Vernaglione); Cerignola-Manfredonia-Accadia (A. Specchio); Policlinico Foggia (G. Stallone); San Severo e Sannicandro G.co (R. Dell'Aquila); San Giovanni Rotondo (F. Aucella); Galatina (G. Sandri); ScorranoPoggiardo (F. Russo); PO V. Fazzi-Lecce (M. Napoli); 
Martina Franca (A. Marangi); SS Annunziata-Taranto (L. Morrone); Manduria/Grottaglie (C. Di Stratis);

Sardegna: Dialisi San Salvatore-Cagliari (A. Fresu); Kinetika-Quartu Sant'Elena (CA) (F. Cicu); ASSL Cagliari (S. Murtas); Casa di cura-Decimomannu (O. Manca); Cagliari Brotzu (A. Pani); Carbonia (M. Pilloni); Carbonia-Iglesias-CAD Buggerru-CAL Carloforte (R. Pistis); ASSL Sanluri-San Gavino (M. Cadoni); Lanusei (B. Contu); Nuoro (F. Logias); PO San Martino-Oristano (R. Ivaldi); Tempio Pausania (S. Fancello); Ospedale ASSL Sassari (M. Cossu); PO Merlo—La Maddalena (G. Lepori); Arzachena-Olbia (G. Lepori);

Sicilia: Diaverum Sciacca-Sciacca (S. Vittoria); BIOS-MEDIC-S.M. Belice (E. Battiati); AuroraAgrigento (M. Arnone); Canicattì-Canicattì (M. Romè); Centro Dialisi-Lampedusa e Linosa (A. Barbera); Ospedale San Giovanni Di Dio-Agrigento (A. Granata); Dialisi Aspert-Bivona (AG) (G. Collura); Centro Emodialisi Ippocrate-Agrigento (C. Lo Dico); AO Giovanni Paolo II-Sciacca (G. Pugliese); CAL Dialisi PO Mussomeli-Caltanissetta (E. Di Natale); Ambulatorio Nisseno di Emodialiei-Caltanissetta (G. Rizzari); Nefrologico Etneo (L. Cottone); CCMC Centro Catanese di Medicina e Chirurgia (N. Longo); Osp. Santa Marta e Santa Venera-Acireale (G. Battaglia); AO San Marco-Catania (C. Marcantoni); Ospedale Gravina Santo Pietro-Caltagirone (G. Giannetto); Ambulatorio Klotho Srl (G. Tumino); Etna Dialisi-Randazzo (CT) (F. Randazzo); CEB SRL-Belpasso (L. Bellissimo); Ambulatorio Azzurra-Catania (F. Lo Faro); Diaverum del Principe-Catania (F. Grippaldi); ARNAS Garibaldi Catania-Catania (S. Urso); Diaverum PaternòPaternò (CT) (G. Quattrone); Ospedale Chiello-Piazza Armerina (I. Todaro); PO Umberto I Enna-Enna (D. Vincenzo); Diaverum-Nissoria (A. Murgo); Diaverum Barcellona P.G.-Barcellona P.G. (M. Masuzzo); Centro Dialisi Omega-Messina (A. Pisacane); AO Papardo-Messina (P. Monardo); Policlinico Messina (D. Santoro); Lipari-PO Fogliani-Milazzo (M. Pontorierro); Santo Stefano di Camastra (C. Quari); San Filippo Dial Center-Brolo (A. Bauro); Nefrologia Pediatrica Messina (R. R.Chimenz); Emodialisi Sparviero-Taormina (D. Alfio); PO Barone MatteoPatti (F. Girasole); ADTR Palermo-Palermo (A. Lo Cascio); Centro Siciliano di Nefr. E Dialisi-Cefalù (A. Caviglia); Centro Medico Nefrologico-Termini Imerese (F. Tornese); Petralia Soprana-Petralia Soprana (F. Sirna); DIBA SRL (C. Altieri); ARNAS Civico Palermo-Palermo (R. Cusumano); Cepidial srl (V. Saveriano); M. Malpighi-Partinico (A. La Corte); Centro Emodialitico Meridionale-Palermo (G. Locascio); Nefrologia Pediatrica ARNAS Civico-
Palermo (U. Rotolo); Nefrologia e Dialisi srl (M. Romè); ASP 7 Ragusa-Ragusa (S. Musso); Dialisi San LucaLentini (SR) (L. Risuglia); Diaverum Brucoli-Brucoli (G. Blanco); Nefral-Noto (G. Minardo); DiaverumLentini (S.Castellino); Sirnephros-Siracusa (Z. Zappulla); PO Avola (S. Randone); Dialisi AretuseaSiracusa (M. Di Francesca); Sirnephros-Pachino (C. C. Cassetti); UOSD Emodialisi-Marsala (G. Oddo); PO Castelvetrano-Castelvetrano (G. Buscaino); Emodialisi Mucaria-Alcamo (F. Mucaria); ASP Trapani-Trapani (V. Ignazio Barraco); Emodialisi Mucaria-Alcamo (A. Di Martino); Emodialisi Mucaria-Valderice (F. Mucaria); Diaverum Marsala (D. Rallo);

Toscana: Ospedale San Miniato-Empoli (L. Dani); Careggi Firenze (G. Campolo); Firenze Santa Maria Nuova-Firenze (f. Manescalchi); SOC Nefrologia e Dialisi Firenze 2-Firenze (M. Biagini); Lucca-Barga (M. Agate); Versilia (V. Panichi); Ospedale ApuaneMassa Carrara (A. Casani); Massa Marittima (L. Traversari); AOU Senese-Siena (G. Garosi);

Trentino Alto Adige: Trento (G. Brunori); Bolzano (M. Tabbì);

Umbria: Assisi-Castiglione del Lago (A. Selvi); Orvieto-Amelia (L. Cencioni); AO Terni (R. Fagugli); AO Perugia (F. Timio); Citta di Castello (A. Leveque);

Valle d'Aosta: Aosta (M. Manes);

Veneto: Piove di Sacco (G. Mennella); Padova (L. Calò); Rovigo Adria Trecenta (F. Fiorini); Castelfranco Veneto (C Abaterusso); Conegliano (P. Calzavara); Treviso (M. Nordio); Ospedale dell'Angelo-MestreDolo e Mirano (G. Meneghel); AULSS4 Veneto Orientale (C. Bonesso); Borgo Trento e Borgo RomaSan Bonifacio-Verona (G. Gambaro); Legnago (C. Rugiu); Bassano del Grappa (R. Dell'Aquila); SantorsoBassano (R. Dell'Aquila); Ospedale San BortoloVicenza (C. Ronco); Villafranca e Caprino (C. Rugiu).

\section{References}

1. World Health Organization, WHO (2020) Coronavirus disease (COVID-19) pandemic. https://www.who.int/emergencies/disea ses/novel-coronavirus-2019. Accessed 23 Apr 2020

2. Remuzzi A, Remuzzi G (2020) COVID-19 and Italy: what next? The Lancet 395(10231):1225-1228. https://doi.org/10.1016/ S0140-6736(20)30627-9

3. Onder G, Rezza G, Brusaferro S (2020) Case-fatality rate and characteristics of patients dying in relation to COVID-19 in Italy. JAMA. https://doi.org/10.1001/jama.2020.4683

4. Center for Systems Science Engineering Johns Hopkins University (2020) COVID-19 World Map. @JohnsHopkins. https://coron avirus.jhu.edu/map.html. Accessed 30 Apr 2020

5. EpiCentro, Istituto Superiore di Sanità (2020) COVID-19 integrated surveillance: key national data. https://www.epicentro. 
iss.it/en/coronavirus/sars-cov-2-integrated-surveillance-data. Accessed 23 Apr 2020

6. Chen J, Lu H, Melino G, Boccia S, Piacentini M, Ricciardi W, Wang Y, Shi Y, Zhu T (2020) COVID-19 infection: the China and Italy perspectives. Cell Death Dis 11(6):438. https://doi. org/10.1038/s41419-020-2603-0

7. Yang J, Zheng Y, Gou X, Pu K, Chen Z, Guo Q, Ji R, Wang H, Wang Y, Zhou Y (2020) Prevalence of comorbidities and its effects in patients infected with SARS-CoV-2: a systematic review and meta-analysis. Int J Infect Dis 94:91-95. https://doi. org/10.1016/j.ijid.2020.03.017

8. Rombola G, Brunini F (2020) COVID-19 and dialysis: why we should be worried. J Nephrol 33(3):401-403. https://doi. org/10.1007/s40620-020-00737-w

9. ERA-EDTA (2020) ERACODA: the ERA-EDTA covid-19 database for patients on dialysis or living with a kidney transplant. https://www.era-edta.org/en/covid-19-news-and-information/. Accessed 4 May 2020

10. SARS-CoV-2 Surveillance Group, Istituto Superiore di Sanità (2020) Characteristics of COVID-19 patients dying in Italy. https://www.epicentro.iss.it/en/coronavirus/sars-cov-2-analy sis-of-deaths. Accessed 1 June 2020

11. Malberti F, Pecchini P, Marchi G, Foramitti M (2020) When a nephrology ward becomes a COVID-19 ward: the Cremona experience. J Nephrol. https://doi.org/10.1007/s40620-02000743-y

12. La Milia V, Bacchini G, Bigi MC, Casartelli D, Cavalli A, Corti M, Crepaldi M, Limardo M, Longhi S, Manzoni C, Ravasi C, Stucchi V, Viganò S (2020) COVID-19 outbreak in a large hemodialysis centre in Lombardy, Italy. Kidney Int Rep. https ://doi.org/10.1016/j.ekir.2020.05.019

13. Alberici F, Delbarba E, Manenti C, Econimo L, Valerio F, Pola A, Maffei C, Possenti S, Lucca B, Cortinovis R, Terlizzi V, Zappa M, Sacca C, Pezzini E, Calcaterra E, Piarulli P, Guerini A, Boni F, Gallico A, Mucchetti A, Affatato S, Bove S, Bracchi M, Costantino EM, Zubani R, Camerini C, Gaggia P, Movilli E, Bossini N, Gaggiotti M, Scolari F (2020) A report from the Brescia Renal COVID Task Force on the clinical characteristics and short-term outcome of hemodialysis patients with SARS-CoV-2 infection. Kidney Int. https://doi.org/10.1016/j. kint.2020.04.030

14. Alberici F, Delbarba E, Manenti C, Econimo L, Valerio F, Pola A, Maffei C, Possenti S, Piva S, Latronico N, Foca E, Castelli F, Gaggia P, Movilli E, Bove S, Malberti F, Farina M, Bracchi M, Costantino EM, Bossini N, Gaggiotti M, Scolari F, Brescia Renal CTF (2020) Management of patients on dialysis and with kidney transplant during SARS-COV-2 (COVID-19) pandemic in Brescia, Italy. Kidney Int Rep. https://doi.org/10.1016/j. ekir.2020.04.001

15. Manganaro $\mathrm{M}$, Baldovino $\mathrm{S}$, Working group of the $\mathrm{P}$, Aosta Valley Section of the SIN (2020) First considerations on the SARS-CoV-2 epidemic in the dialysis units of piedmont and Aosta Valley, Northern Italy. J Nephrol 33(3):393-395. https:// doi.org/10.1007/s40620-020-00732-1

16. Società Italian di Nefrologia (2020) DialMap: national map of nephrology and dialysis centers. https://dialmap.it/. Accessed 31 Mar 2020

17. Cochran WG (1977) Sampling techniques. Wiley series in probability and mathematical statistics, 3rd edn. Wiley, New York

18. Lavrakas PJ (2008) Encyclopedia of survey research methods. SAGE Publications, Thousand Oaks

19. Kelley K, Clark B, Brown V, Sitzia J (2003) Good practice in the conduct and reporting of survey research. Int J Qual Health Care 15(3):261-266. https://doi.org/10.1093/intqhc/mzg031

20. Società Italiana di Nefrologia (2020) SIN-Covid survey phase 1: pilot study. https://sinitaly.org/wp-content/uploads/2020/04/
Survey-Covid-19-paz-dialisi-e-centri-dialisi.pdf. Accessed 24 Mar 2020

21. Gruppo di Lavoro ISS Diagnostica e sorveglianza microbiologica COVID-19 (2020) Recommendations for sampling, storing and analysis of oro/nasopharyngeal swab for COVID-19 diagnosis. Rapporti ISS COVID-19 (11):7

22. Cummings $P$ (2019) Analysis of incidence rates. CRC Press, Taylor \& Francis Group, Boca Raton

23. Fleiss JL, Levin B, Paik MC (2003) Statistical methods for rates and proportions. Wiley series in probability and statistics, 3rd edn. Wiley, Hoboken

24. Istituto Nazionale di Statistica - ISTAT (2020) Confini delle unità amministrative a fini statistici al $1^{\circ}$ gennaio 2020. https:// www.istat.it/it/archivio/222527. Accessed 23 Apr 2020

25. Kirby RS, Delmelle E, Eberth JM (2017) Advances in spatial epidemiology and geographic information systems. Ann Epidemiol 27(1):1-9. https://doi.org/10.1016/j.annep idem.2016.12.001

26. Società Italiana di Nefrologia (2020) Coronavirus disease (COVID-19) pandemic. https://sinitaly.org/coronavirus/. Accessed 1 June 2020

27. Icona members, Gambaro G, Piccoli GB (2020) Nothing will ever be as before. Reflections on the COVID-19 epidemics by nephrologists in eleven countries. J Nephrol. https://doi. org/10.1007/s40620-020-00756-7

28. Rombola G, Heidempergher M, Pedrini L, Farina M, Aucella F, Messa P, Brunori G (2020) Practical indications for the prevention and management of SARS-CoV-2 in ambulatory dialysis patients: lessons from the first phase of the epidemics in Lombardy. J Nephrol 33(2):193-196. https://doi.org/10.1007/s4062 0-020-00727-y

29. Basile C, Combe C, Pizzarelli F, Covic A, Davenport A, Kanbay M, Kirmizis D, Schneditz D, van der Sande F, Mitra S (2020) Recommendations for the prevention, mitigation and containment of the emerging SARS-CoV-2 (COVID-19) pandemic in haemodialysis centres. Nephrol Dial Transplant 35(5):737-741. https://doi.org/10.1093/ndt/gfaa069

30. Meijers B, Messa P, Ronco C (2020) Safeguarding the maintenance hemodialysis patient population during the Coronavirus Disease 19 pandemic. Blood Purif 49(3):259-264. https://doi. org/10.1159/000507537

31. Vistoli F, Furian L, Maggiore U, Caldara R, Cantaluppi V, Ferraresso $\mathrm{M}$, Zaza G, Cardillo M, Biancofiore G, Menichetti F, Russo A, Turillazzi E, Di Paolo M, Grandaliano G, Boggi U (2020) COVID-19 and kidney transplantation: an Italian survey and consensus. J Nephrol. https://doi.org/10.1007/s40620-02000755-8

32. Moriyama M, Hugentobler WJ, Iwasaki A (2020) Seasonality of respiratory viral infections. Annu Rev Virol. https://doi. org/10.1146/annurev-virology-012420-022445

33. Sajadi MM, Habibzadeh P, Vintzileos A, Shokouhi S, MirallesWilhelm F, Amoroso A (2020) Temperature, humidity, and latitude analysis to estimate potential spread and seasonality of Coronavirus Disease 2019 (COVID-19). JAMA Netw Open 3(6):e2011834. https://doi.org/10.1001/jamanetworkopen .2020 .11834

34. Agarwal R (2020) The aftermath of coronavirus disease of 2019: devastation or a new dawn for nephrology? Nephrol Dial Transplant. https://doi.org/10.1093/ndt/gfaa094

35. Farkash EA, Wilson AM, Jentzen JM (2020) Ultrastructural evidence for direct renal infection with SARS-CoV-2. J Am Soc Nephrol. https://doi.org/10.1681/ASN.2020040432

36. Ronco C, Reis T (2020) Kidney involvement in COVID-19 and rationale for extracorporeal therapies. Nat Rev Nephrol 16(6):308-310. https://doi.org/10.1038/s41581-020-0284-7 
37. Fanelli V, Fiorentino M, Cantaluppi V, Gesualdo L, Stallone G, Ronco C, Castellano G (2020) Acute kidney injury in SARS-CoV-2 infected patients. Crit Care 24(1):155. https://doi. org/10.1186/s13054-020-02872-z
Publisher's Note Springer Nature remains neutral with regard to jurisdictional claims in published maps and institutional affiliations.

\section{Affiliations}

\section{Giuseppe Quintaliani ${ }^{1} \cdot$ Gianpaolo Reboldi ${ }^{2}$ - Anteo Di Napoli ${ }^{3} \cdot$ Maurizio Nordio ${ }^{4}$ - Aurelio Limido ${ }^{5}$. Filippo Aucella ${ }^{6} \cdot$ Piergiorgio Messa $^{7}$. Giuliano Brunori ${ }^{1,8}$ on behalf of the Italian Society of Nephrology COVID-19 Research Group}

1 Italian Society of Nephrology, Viale dell'Università, 11, 00185 Roma, RM, Italy

2 Department of Medicine, University of Perugia, Perugia, Italy

3 National Institute for Health, Migration and Poverty (INMP), Rome, Italy

4 Unit of Nephrology, General Hospital, Piazzale Ospedale, 23, 31100 Treviso, Italy

5 Nephrology and Dialysis Unit, ASST Fatebenefratelli e Oftalmico, Milan, Italy
6 Nephrology and Dialysis Unit, IRCCS “Casa Sollievo Della Sofferenza" Scientific Institute for Research and Health Care, San Giovanni Rotondo, Italy

7 Division of Nephrology, Dialysis and Renal Transplantation, Fondazione IRCCS Cà Granda Ospedale Maggiore Policlinico, Milano, Italy

8 Nephrology and Dialysis Unit, Hospital of Trento, Trento, Italy 